\title{
Efficacy of buprenorphine for management of surgical castration pain in piglets
}

\author{
Abbie V. Viscardi ${ }^{*}$ (D) and Patricia V. Turner
}

\begin{abstract}
Background: Surgical castration is a painful procedure, performed routinely on commercial pig farms to prevent boar taint and reduce aggression. The objectives of this study were to assess the efficacy of $0.04 \mathrm{mg} / \mathrm{kg}$ buprenorphine (BUP) in reducing pain in castrated piglets, using behavioral indicators and vocalization analysis. This study also sought to further validate the Piglet Grimace Scale (PGS) as a pain assessment tool.

A pilot study first assessed the safety of BUP or $0.2 \mathrm{mg} / \mathrm{kg}$ butorphanol administration to piglets ( $n=4$ per treatment). When no side effects were noted with BUP, ten litters of 5-day old piglets ( $n=60$ total, 15 per treatment group) were used, and randomly assigned to one of four possible treatments: BUP (castrated or uncastrated), saline, or sham. Treatments were administered as an intramuscular injection 20 min prior to surgical castration. Piglets were video recorded $1 \mathrm{~h}$ pre-procedure, post-castration for $8 \mathrm{~h}$ and for another hour, $24 \mathrm{~h}$ post-procedure. Behaviors were scored continuously for the first 15 min of each hour and 511 still-images of piglet faces were scored using the PGS. Vocalizations were recorded from each piglet at three points in the study: at initial handling, injection, and castration.

Results: Butorphanol caused some piglets to become groggy and vomit and was not further evaluated. BUP-castrated piglets demonstrated significantly fewer pain behaviors and less facial grimacing compared to saline-treated pigs $(P<0.0001$ and $P=0.0073$, respectively). There was no difference between the pain behaviours displayed by BUP-castrated piglets compared to BUP-uncastrated and sham piglets $(P=0.9986$ and $P=0.7484)$. There was also no difference in PGS score between BUP-castrated and BUP-uncastrated piglets $(P=0.9376)$. Piglets in the BUP-castrated group produced vocalizations of similar frequency, amplitude, power, and energy to saline-treated piglets.

Conclusions: Buprenorphine was highly effective in alleviating castration-associated pain behaviors and facial grimacing in piglets, without causing any obvious side effects. Its administration did not reduce piglet vocalizations at the time of castration. The PGS corresponded well to piglet pain behaviors and has utility as a pain assessment tool.
\end{abstract}

Keywords: Animal welfare, Analgesia, Buprenorphine, Pain assessment, Piglet, Castration, Behavior, Piglet grimace scale

\section{Background}

Surgical castration is a procedure performed routinely on piglets in North America to prevent boar taint and minimize agonistic behaviors [1]. It causes acute pain in piglets, as evidenced by behavioral and physiologic alterations after castration, including rump scratching, body spasms, high-frequency vocalizations, and increased blood cortisol levels [2-4]. However, piglets are generally not provided analgesia or anesthesia for pain relief. Canada and countries in the EU have recognized this as a significant piglet welfare concern and have guidelines that now require analgesia administration $[5,6]$. Nonsteroidal

\footnotetext{
* Correspondence: aviscard@uoguelph.ca

Department of Pathobiology, University of Guelph, 50 Stone Road E, Guelph, ON N1G 2W1, Canada
}

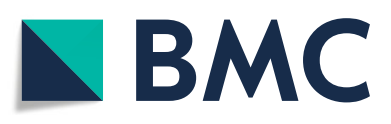

(c) The Author(s). 2018 Open Access This article is distributed under the terms of the Creative Commons Attribution 4.0 International License (http://creativecommons.org/licenses/by/4.0/), which permits unrestricted use, distribution, and reproduction in any medium, provided you give appropriate credit to the original author(s) and the source, provide a link to the Creative Commons license, and indicate if changes were made. The Creative Commons Public Domain Dedication waiver (http://creativecommons.org/publicdomain/zero/1.0/) applies to the data made available in this article, unless otherwise stated.

anti-inflammatory drugs (NSAIDs), such as meloxicam and ketoprofen, are currently recommended for use in piglets to manage pain, yet previous research found the label dose $(0.4 \mathrm{mg} / \mathrm{kg})$ of meloxicam, a high dose $(1.0 \mathrm{mg} / \mathrm{kg})$ of meloxicam, or $6.0 \mathrm{mg} / \mathrm{kg}$ ketoprofen to be ineffective at alleviating surgical castration pain in piglets $[4,7]$. The analgesic capacity of an NSAID is limited by the degree of tissue trauma caused by the surgical castration procedure, as a significant mechanism underlying NSAID-induced pain mitigation is suppression of pro-inflammatory prostaglandin synthesis [8]. Opioids, such as buprenorphine and butorphanol, are more potent analgesic drugs, binding to $\mu, \delta$, and $\kappa$ opioid receptors in the brain, spinal cord, and peripherally to suppress central pain signal transmission [9]. Butorphanol has been used in combination with 
various drugs, such as xylazine-ketamine, medetomidine, azaperone-detomidine-ketamine, and midazolam-ketamine, in pigs to prolong sedation [10-13]. Butorphanol alone was found to be ineffective at reducing pain behaviors of piglets castrated at 8 weeks-old [14]. Buprenorphine has demonstrated efficacy in reducing pain and lameness in pigs $[15$, 16]. The ability of butorphanol and buprenorphine to alleviate pain in 5-day-old piglets following castration has not been assessed.

The Piglet Grimace Scale (PGS) is a novel pain assessment tool that examines specific facial feature alterations in piglets in response to an acutely painful event [17]. Similar species-specific scales have been developed for mice, rats, rabbits, horses, sheep, and lambs [18-23]. These scales are of interest for their non-invasive nature and ability to rapidly detect pain [24]. For appropriate validation of these scales, they must correspond well to known indicators of pain, such as behavior.

The objectives of this study were first to determine the safety of buprenorphine and butorphanol administration to piglets, and then to assess their efficacy in reducing pain in castrated piglets, using behavioral indicators and vocalization analysis. We hypothesized that piglets receiving an opioid pre-castration would show a significant reduction in vocalizations and pain behaviors. This study also sought to further validate the PGS by comparing it against castration-related pain behaviors. The findings of this work will be important for appropriate analgesic recommendations to alleviate piglet pain post-castration, leading to improved animal welfare, a topic of increasing societal concern [25].

\section{Results}

Part I- opioid pilot study

\section{Behavioral observations}

Approximately 30 min post-injection, piglets administered butorphanol became groggy, unable to stand or walk, and two of the four animals vomited. They remained in the farrowing pen, and the observers ensured there was enough distance between them and the sow to eliminate their risk of being crushed. Butorphanol-treated piglets did not experience any severe side effects to the drug (e.g., respiratory depression), and they fully recovered approximately $1.5 \mathrm{~h}$ post-injection. There were no side effects noted with buprenorphine administration.

\section{Part II- buprenorphine definitive trial \\ Behavioral observations}

Four individual behaviors (lying: $P<0.0001$, standing: $P<$ 0.0001 , tail wagging: $P<0.0001$, and walking: $P<0.0001$ ) and both grouped behaviors (active: $P<0.0001$, and pain: $P<0.0001$ ), were affected by treatment across all time points. Piglets in the BUP-castrated and BUP-uncastrated treatment groups spent significantly less time lying and more time standing, walking, and engaged in more active behaviours than piglets in the saline and sham treatment groups $(P<0.05)$ (Fig. 1). Saline-treated piglets wagged their tails and demonstrated significantly more pain behaviors than piglets in all other treatment groups $(P<0.05)$ (Fig. 2).

Eight individual behaviors and both grouped behaviors (active and pain) were significantly affected by time across the observation period: awake inactive $(P<0.0001)$, lying $(P=0.0016)$, sleeping $(P<0.0001)$, standing $(P=0.0004)$, suckling $(P=0.0288)$, tail wagging $(P<0.0001)$, walking $(P<0.0001)$, chewing $(P=0.0324)$, active $(P=0.0030)$, and pain $(P<0.0001)$. Regardless of treatment, at $0 \mathrm{~h}$ post-castration, piglets were significantly more active, spending more time standing and walking, and less time lying and sleeping compared to piglets at $4 \mathrm{~h}, 5 \mathrm{~h}$, and $7 \mathrm{~h}$ post-procedure $(P<0.05)$. No rump scratching or trembling behavior was observed from any piglet pre-procedure and there were no significant behavioral differences between any of the treatment groups pre-castration $(P>0.05) \quad$ (Table 1). Suckling and chewing behaviors were not significant after the Tukey-Kramer adjustment.

A significant time $\mathrm{x}$ treatment effect was found for lying $(P=0.0300)$, standing $(P=0.0228)$, tail wagging $(P=0.0488)$, active $(P=0.0259)$, and pain $(P=0.0002)$. At $4 \mathrm{~h}$ post-castration, sham piglets were significantly less active, spending more time lying and less time standing than BUP-castrated piglets at $0 \mathrm{~h}, 2 \mathrm{~h}$, and $3 \mathrm{~h}$, and BUP-uncastrated piglets at $0 \mathrm{~h}$ and $1 \mathrm{~h}(P<$ 0.05 ) (Fig. 3). At $24 \mathrm{~h}$ post-castration, saline-treated piglets demonstrated significantly more tail wagging and pain behaviors than BUP-castrated piglets at $3 \mathrm{~h}$, $5 \mathrm{~h}, 6 \mathrm{~h}$, and $24 \mathrm{~h}$, BUP-uncastrated piglets at $6 \mathrm{~h}$ and $24 \mathrm{~h}$, and sham piglets at all post-castration time points $(P<0.05)$ (Fig. 4). Compared to themselves, saline-treated piglets displayed significantly more pain

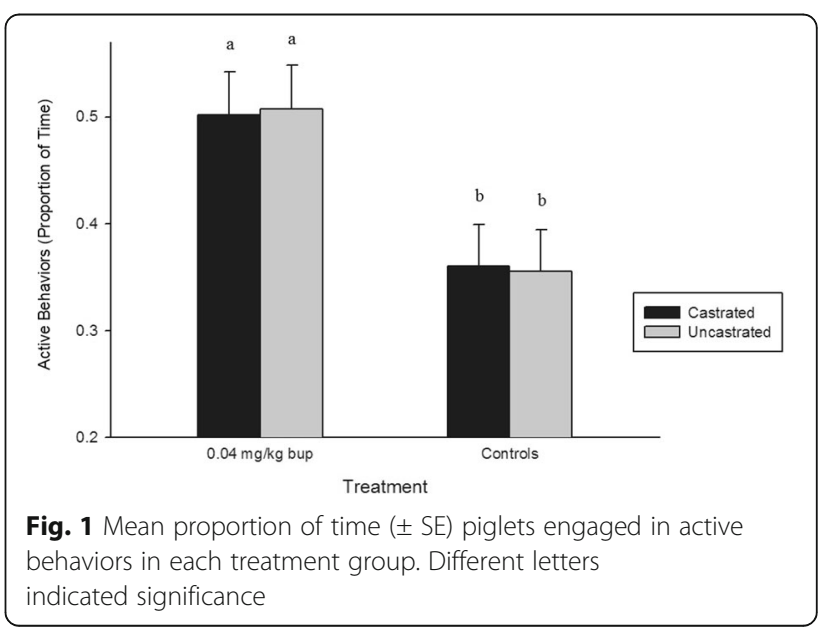




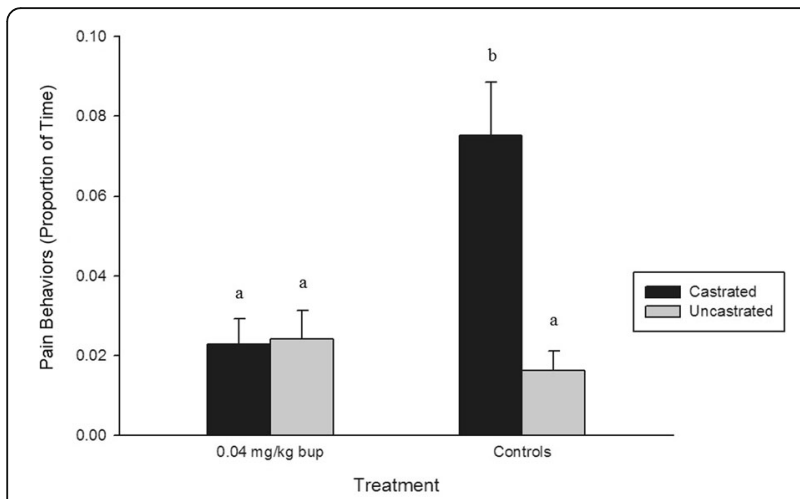

Fig. 2 Mean proportion of time $( \pm$ SE) piglets displayed pain behaviors in each treatment group. Different letters indicated significance

behaviors at $24 \mathrm{~h}$ than at $0 \mathrm{~h}, 1 \mathrm{~h}, 3 \mathrm{~h}$, and $5 \mathrm{~h}-7 \mathrm{~h}$ post-castration.

\section{Piglet grimace scale}

There was a significant treatment effect on PGS score $(P=$ 0.0003) (Fig. 5). BUP-castrated and BUP-uncastrated piglets grimaced significantly less than both saline (BUP-castrated: $P=0.007$, and BUP-uncastrated: $P=0.001$ ) and sham (BUP-castrated: $P=0.049$, and BUP-uncastrated: $P=0.013$ ) treatment groups. Across all time points, there was no significant difference in PGS score between BUP-castrated and BUP-uncastrated piglets $(P=0.944)$, nor was there a difference found between piglets in the saline and sham treatment groups $(P=0.974)$.

\section{Vocalization}

For both castrated-treatment groups, the scrotal incision produced piglet vocalizations that were significantly lower in frequency, amplitude, and power compared to the IM injection $(P=0.0003, P=0.007$, and $P=0.0001$, respectively). When compared to castration (i.e., pulling and tearing of the spermatic cord to remove testicles), the scrotal incision produced piglet vocalizations significantly lower in frequency and power $(P<0.0001$ for both). Injecting piglets resulted in vocalizations that were significantly higher in frequency, amplitude and power compared to marking piglets $(P=0.02, P=0.04$, and $P=0.02$, respectively) (Fig. 6).

Piglets in the BUP-castrated treatment group produced vocalizations significantly higher in frequency, power, and energy compared to piglets in the sham group ( $P=0.04, P=0.02$, and $P=0.04$, respectively) (Fig. 7). Buprenorphine administration did not reduce piglet vocalizations at the time of castration; piglets in the BUP-castrated group produced vocalizations of similar frequency, amplitude, power, and energy to saline-treated piglets $(P=1.00$ for all).

\section{Weight analysis}

Sham piglets, with an average BW of $1.95 \pm 0.14 \mathrm{~kg}$, weighed significantly less than piglets in all other treatment groups (BUP-castrated: $2.48 \pm 0.13 \mathrm{~kg}, P=0.0044$; BUP-uncastrated: $2.32 \pm 0.12 \mathrm{~kg}, P=0.045$; saline: $2.44 \pm$ $0.14 \mathrm{~kg}, P=0.009$ ).

\section{Discussion}

This study examined buprenorphine efficacy in mitigating post-castration pain in piglets. Buprenorphine significantly reduced piglet pain behaviors such that no differences were observed between BUP- castrated and BUP- uncastrated or sham piglets at any post-castration time point (up to $24 \mathrm{~h}$ ). Castrated and uncastrated

Table 1 Behavioral analysis of piglets $(n=60)$ pre-treatment and post-treatment across all litters and timepoints. Values presented are the proportional means \pm SE

\begin{tabular}{|c|c|c|c|c|c|c|c|c|c|c|}
\hline & \multirow[t]{2}{*}{ Behavior $^{c}$} & \multicolumn{2}{|l|}{ Pre-Castration } & \multicolumn{7}{|l|}{ Post-Castration } \\
\hline & & $\begin{array}{l}\text { Treatment } P \text { - } \\
\text { value }\end{array}$ & $\begin{array}{l}\text { Pre- } \\
\text { Treatment }\end{array}$ & $\begin{array}{l}\text { Treatment P- } \\
\text { value }\end{array}$ & $\begin{array}{l}\text { Time P- } \\
\text { value }\end{array}$ & $\begin{array}{l}\text { Time*Treatment } \\
\text { P-value }\end{array}$ & $\begin{array}{l}0.04 \mathrm{mg} / \mathrm{kg} \\
\text { BUP cast }\end{array}$ & $\begin{array}{l}0.04 \mathrm{mg} / \mathrm{kg} \text { BUP } \\
\text { uncast }\end{array}$ & Saline & Sham \\
\hline \multirow[t]{9}{*}{$\begin{array}{l}\text { Proportion } \\
\text { (duration) }\end{array}$} & $\begin{array}{l}\text { Awake } \\
\text { inactive }\end{array}$ & 0.9704 & $0.64 \pm 0.05$ & 0.6749 & $<.0001$ & 0.2277 & $0.53 \pm 0.02$ & $0.50 \pm 0.02$ & $0.54 \pm 0.03$ & $0.52 \pm 0.03$ \\
\hline & Lying & - & $0.53 \pm 0.08$ & $<.0001$ & 0.0001 & 0.0300 & $0.49 \pm 0.04^{\mathrm{a}}$ & $0.44 \pm 0.04^{\mathrm{a}}$ & $0.68 \pm 0.04^{b}$ & $0.67 \pm 0.03^{b}$ \\
\hline & $\begin{array}{l}\text { Nosing } \\
\text { udder }\end{array}$ & 0.0551 & $0.23 \pm 0.05$ & 0.0248 & 0.0047 & 0.9439 & $0.15 \pm 0.03$ & $0.17 \pm 0.03$ & $0.23 \pm 0.04$ & $0.25 \pm 0.04$ \\
\hline & Sleeping & 0.6062 & $0.28 \pm 0.06$ & 0.0187 & $<.0001$ & 0.7070 & $0.35 \pm 0.07$ & $0.32 \pm 0.07$ & $0.45 \pm 0.07$ & $0.49 \pm 0.07$ \\
\hline & Standing & 0.7142 & $0.44 \pm 0.08$ & $<.0001$ & $<.0001$ & 0.0228 & $0.48 \pm 0.08^{a}$ & $0.52 \pm 0.07^{a}$ & $0.28 \pm 0.06^{b}$ & $0.29 \pm 0.06^{b}$ \\
\hline & $\begin{array}{l}\text { Tail } \\
\text { wagging }\end{array}$ & 0.4929 & $0.02 \pm 0.00$ & $<.0001$ & 0.4166 & 0.0488 & $0.00 \pm 0.00^{a}$ & $0.00 \pm 0.00^{a}$ & $0.07 \pm 0.01^{b}$ & $0.01 \pm 0.00^{\mathrm{a}}$ \\
\hline & Walking & 0.2945 & $0.16 \pm 0.04$ & $<.0001$ & 0.0001 & 0.3728 & $0.23 \pm 0.03^{a}$ & $0.25 \pm 0.03^{\mathrm{a}}$ & $0.07 \pm 0.01^{b}$ & $0.09 \pm 0.02^{b}$ \\
\hline & Active $^{d}$ & 0.6394 & $0.47 \pm 0.07$ & $<.0001$ & $<.0001$ & 0.0259 & $0.51 \pm 0.06^{\mathrm{a}}$ & $0.56 \pm 0.06^{a}$ & $0.33 \pm 0.06^{b}$ & $0.33 \pm 0.06^{b}$ \\
\hline & Pain $^{\mathrm{e}}$ & 0.2859 & $0.02 \pm 0.00$ & $<.0001$ & 0.0329 & 0.0002 & $0.02 \pm 0.00^{\mathrm{a}}$ & $0.03 \pm 0.00^{\mathrm{a}}$ & $0.08 \pm 0.01^{b}$ & $0.02 \pm 0.00^{a}$ \\
\hline
\end{tabular}

\footnotetext{
'Only behavior variables that were significant post-treatment are presented

${ }^{\mathrm{d}}$ Active behaviors include: nosing, suckling, walking, chewing, playing, running

ePain behaviors include: stiffness, trembling, spasms, tail wagging and scratching
}

${ }^{a, b}$ Means with different superscripts in the same row differ significantly $(P<0.05)$; entries in italic font are statistically significant 


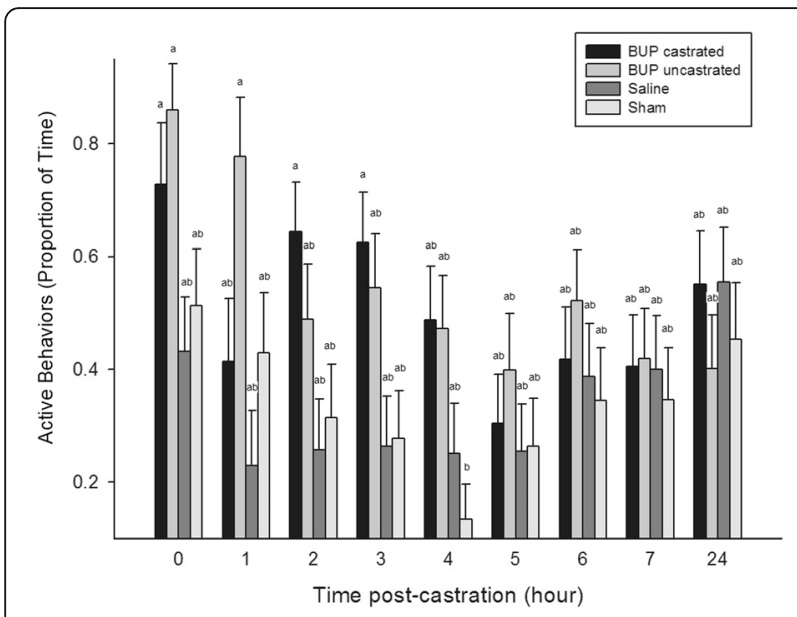

Fig. 3 Mean proportion of time ( \pm SE) piglets engaged in active behaviors within each treatment group across the observation period. Different letters indicated significance

buprenorphine-treated piglets were significantly more active than saline-treated pigs, showing no sedative effect with the $0.04 \mathrm{mg} / \mathrm{kg}$ dose. Animals often become less active but more restless when in pain [26]. Restlessness was difficult to assess with the ethogram used, but increased pain behavior and decreased activity was noted in saline-treated piglets in this study. Results from the treatment control group (i.e., piglets given buprenorphine but uncastrated) also verified no negative behavioral side effects are associated with buprenorphine administration. Saline-treated piglets wagged their tails significantly more than all other treatment groups. An increase in tail wagging after a painful event, such as castration or dehorning, has been observed in piglets, lambs, and calves [2, 7, 2730], suggesting that this may be a useful pain indicator. Note that piglets in this study had not been tail docked

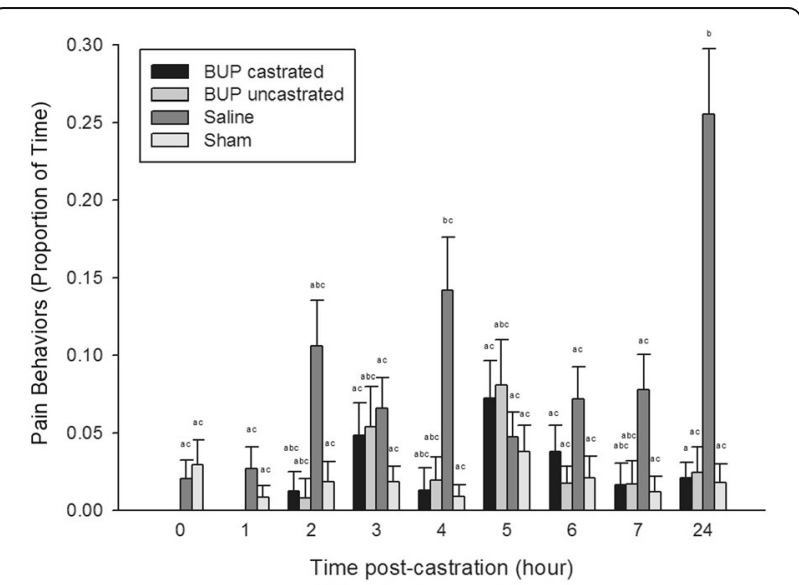

Fig. 4 Mean proportion of time ( \pm SE) piglets demonstrated pain behaviors within each treatment group across the observation period. Different letters indicated significance

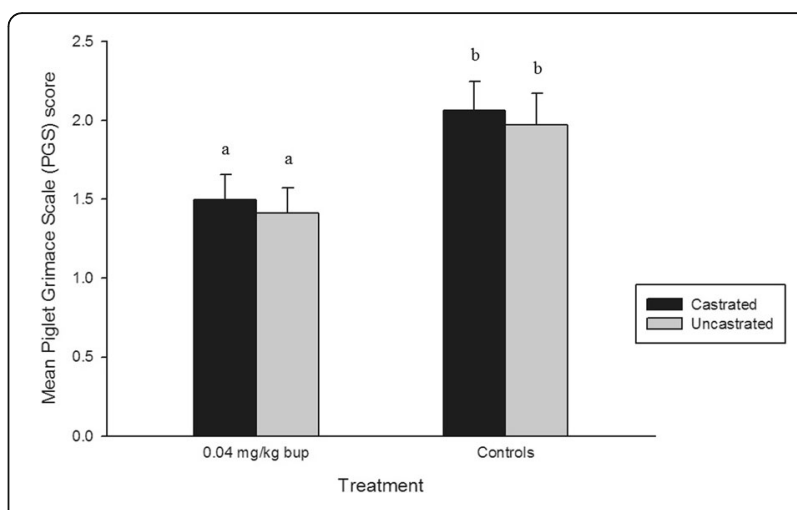

Fig. 5 Mean Piglet Grimace Scale (PGS) scores $( \pm$ SE) in each treatment group. Different letters indicate significance

and thus increases in tail wagging could not be attributed to tail stump hyperalgesia [31].

Increased piglet activity was observed immediately post-castration (at $0 \mathrm{~h}$ ). This may be attributed to the stress of repeated handling, the IM injection and separation from the sow for 20-30 min. Piglets are also generally more active in the early morning and early evening [32]. At $24 \mathrm{~h}$ post-castration, saline-treated piglets demonstrated significantly more tail wagging and pain behaviors than any other treatment group and at most other time points. This increase in pain may be due to progression of the inflammatory process [33]. Buprenorphine-castrated piglets might have been expected to display more pain behaviors at $24 \mathrm{~h}$ post-castration, since the maximum duration of action of buprenorphine in swine is $12 \mathrm{~h}$ [34], but this was not observed. Future work should assess piglet pain beyond $24 \mathrm{~h}$ post-castration, to determine whether a single dose of buprenorphine provides sufficient post-castration analgesia for piglets.

After observing the significant sedative and emetic effects associated with butorphanol administration to piglets in the pilot study, this drug was not tested further. The sedative effects put piglets at greater risk of hypothermia or being crushed if they are immediately placed back in their pen, making it an inappropriate opioid for use in piglets. Buprenorphine was determined to be safe and there were no evident side effects in the pilot or definitive studies.

NSAIDs, such as meloxicam and ketoprofen, are licensed for use in swine and are the most practical drugs available for producers to administer to piglets for pain relief [35]. In terms of efficacy, both NSAIDs have had variable success in significantly reducing post-castration pain $[4,36]$. A review of the existing literature by a group of swine experts determined the quality of evidence to support NSAID use was low, and they gave a weak recommendation for the use of NSAIDs to mitigate surgical castration pain [37]. It is clear that a more 


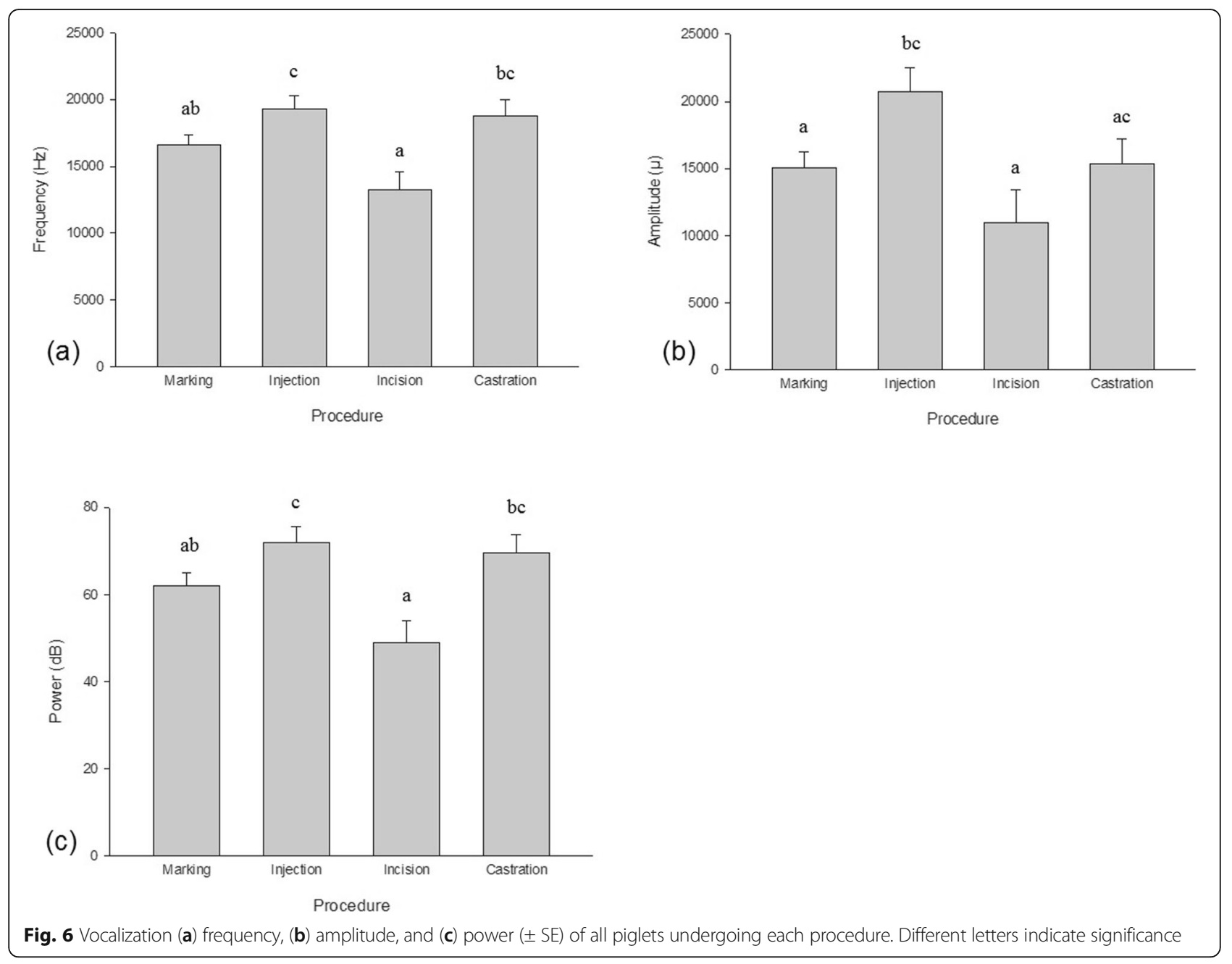

potent drug class, such as opioids, may be required for appropriate pain control in pigs, further evidenced by the results of this study.

Facial action unit analysis is an increasingly popular method to assess pain in animals, because it is non-invasive, quick, and easy to use [38]. To become a validated pain assessment tool, the PGS must be comparable to known indicators of pain. In this study, we compared PGS scores to the pain behaviors displayed by piglets. The observed pain behaviors corresponded perfectly to PGS results for buprenorphine-castrated, buprenorphine-uncastrated, and saline-castrated piglets (e.g., an increase in pain behavior corresponded to higher facial grimacing), and buprenorphine significantly reduced facial grimacing in castrated piglets. However, this was not noted for the sham-uncastrated group. Sham piglets were expected to demonstrate low facial grimacing, high activity, and low pain behaviors, as this group did not receive an IM injection and were not castrated. Instead, they demonstrated high facial grimacing, low activity, and low pain behaviors. The post-study weight analysis revealed that sham piglets as a group weighed significantly less on average than piglets in all other treatment groups. Low body weight (LBW) piglets have low survival rates through the first week of life [39], as they are at greater risk of crushing, starvation, and disease than piglets of average body weight $[40,41]$. LBW piglets tend to miss more nursing bouts and spend more time alone [42]. It may be that the increase in facial grimacing and decrease in activity level of these piglets was due to weakness and discomfort, not pain. This is a confounder in this study and future work should ensure piglet weights are balanced across treatment groups.

Piglets emit distinct vocalizations associated with castration that have been attributed to pain [3, 43]. Buprenorphine did not reduce the frequency, amplitude, power, or energy of these vocalizations at the time of castration. Therapeutic concentrations of buprenorphine $(0.1 \mathrm{ng} / \mathrm{mL})$ are reached rapidly in pigs after IM injection (between 5 and $30 \mathrm{~min}$ ) [32] and piglets were castrated $20 \mathrm{~min}$ after its administration. This suggests that buprenorphine alone does not provide sufficient analgesia to fully mitigate pain 

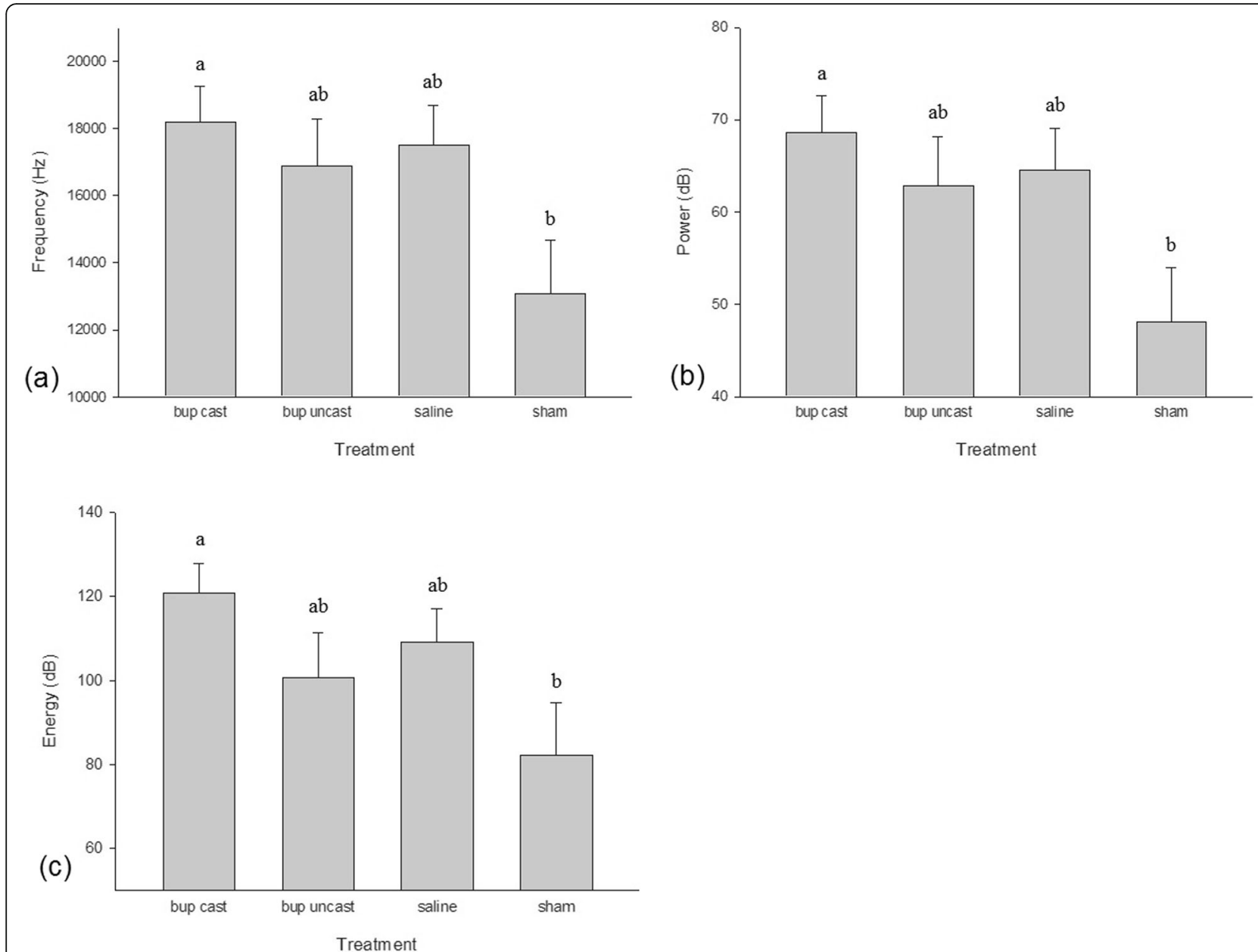

Fig. 7 Vocalization (a) frequency, (b) power, and (c) energy ( \pm SE) of piglets in each treatment group. Different letters indicate significance

associated with surgical castration in conscious piglets. Previous studies have found that surgical castration-related stress vocalizations are reduced by $\mathrm{CO}_{2}$ anesthesia, a combination of ketamine-climazolam-azaperone anesthesia or intratesticular lidocaine injection [44-46]. However, these agents or combinations provide minimal post-operative analgesia and present greater limitations for on-farm use (e.g., sedated piglets can not be returned to the sow until after drug recovery).

The practicality of buprenorphine use on-farm currently is low. While it was highly effective, easy to administer, and one injection provided pain relief for at least $24 \mathrm{~h}$ post-procedure, it is a controlled substance that must be administered by a veterinarian and its use is currently prohibited (illegal) in pigs or other food-producing animals [47, 48]. The opioid abuse epidemic is another issue to consider. With more than 42,000 deaths in the U.S. related to opioid drug overdose in 2016, veterinarians have had to make major adjustments to the type of drugs they send home with clients and carry in their practice to reduce the risk of human abuse $[49,50]$. Farmers appear to be disproportionately at risk, with three-quarters of U.S. farmers and farm workers having reported being directly affected by opioid dependence [51]. While the idea of widespread opioid use on-farm is inconceivable, identification of buprenorphine as a drug that significantly reduced surgical castration pain may encourage other researchers to focus on how to make this highly effective option for piglet pain management practical for use in swine production (e.g., through novel formulation or administration that is safe and limits the risk of abuse).

\section{Conclusions}

Buprenorphine, when administered at $0.04 \mathrm{mg} / \mathrm{kg} \mathrm{IM}$, significantly reduced pain behaviors and facial grimacing in surgically castrated piglets for up to $24 \mathrm{~h}$ post-procedure, without evident adverse effects. It was not able to reduce vocalizations at the time of castration. The PGS corresponds well to the pain behaviors of piglets and has utility as a pain assessment tool. Future work should 
focus on potential solutions to the current limitations of using buprenorphine on-farm, as it is a highly effective analgesic agent that could improve the welfare of millions of piglets undergoing painful procedures each year.

\section{Methods}

This study was conducted at Arkell Swine Research Station, an active research facility supported by the University of Guelph and the Ontario Ministry of Agriculture, Food and Rural Affairs (OMAFRA). All animal use and procedures were approved by the University of Guelph Animal Care Committee (Animal Utilization Protocol \#3350). The institution is registered under the Animals for Research Act of Ontario and holds a Good Animal Practice certificate issued by the Canadian Council on Animal Care.

\section{Part I- opioid pilot study}

Animals and treatments

A total of 8 Yorkshire-Landrace $x$ Duroc male piglets (5-days-old, average $\mathrm{BW}=2.19 \pm 0.07 \mathrm{~kg}$ ) from 2 different litters were used in this pilot study. Sows and piglets were housed in farrowing pens at the University of Guelph Arkell Swine Research Station (Arkell, ON, Canada). The floor space for each pen was $1.8 \mathrm{~m} \times 2.4 \mathrm{~m}(6 \mathrm{ft} . \times 8 \mathrm{ft})$ and the farrowing crate was $0.8 \mathrm{~m} \times 2.3 \mathrm{~m}(2.5 \mathrm{ft} . \times 7.5 \mathrm{ft})$. The farrowing rooms were maintained at ambient temperature $\left(23^{\circ} \mathrm{C} \pm 0.5^{\circ} \mathrm{C}\right)$ with lights on/off at 7:00 am/ 9:00 pm, and additional natural light was provided by windows in each room. Sows were fed ab lib 4 days after farrowing. The creep areas for piglets were heated to approximately $30-35^{\circ} \mathrm{C}$ by means of a heat lamp.

Four piglets from each litter were used and randomly assigned one of two treatments: $0.04 \mathrm{mg} / \mathrm{kg}$ buprenorphine (Vetergesic $0.3 \mathrm{mg} / \mathrm{mL}$; Champion Alstoe Animal Health Inc., Whitby, ON, Canada; extra-label use) or $0.2 \mathrm{mg} / \mathrm{kg}$ butorphanol (Torbugesic $10 \mathrm{mg} / \mathrm{mL}$; Zoetis Inc., Kalamazoo, MI; extra-label use). Both drugs were administered intramuscularly (IM) and doses were derived from the literature [52]. Treatment groups were identified by a symbol ('C' or 'D') marked on the piglet's back with a permanent marker prior to injection, to ensure that those involved in post-castration observations were blinded to treatment. A number was also marked on the back leg of each piglet for individual identification purposes.

\section{Processing procedure}

Piglets were weighed approximately $24 \mathrm{~h}$ prior to the study start for drug dose calculations, and then marked with a symbol and number. On the day of castration, male piglets were removed from their pen, placed in a transport cart, and treatments were administered. Approximately 20 mins later, piglets were surgically castrated by making one vertical incision over each testicle using a scalpel and tearing the spermatic cords. The piglets were then returned to their home pen. Castrations occurred between 8:00 am and 8:30 am and were all done by the same individual (AVV).

\section{Behavior recording}

Live observations were conducted for the first $1 \mathrm{~h}$ post-injection; if piglets responded negatively to the administered drug, they were quickly removed from their pen and assisted. One experienced observer blinded to treatment was placed outside each litter of piglets in this study and was instructed to note any unusual piglet behavior (e.g. grogginess, vomiting, distress, or lying isolated from littermates for an extended period). Video cameras (JVC GZ-E200 full HD Everio Camcorder, Yokohama, Japan) were also placed on tripods outside of the farrowing pens and piglets were video recorded during and after the live observations for $7 \mathrm{~h}$. An individual not involved in the live observations assessed the video footage for behavioral signs of distress related to opioid administration.

\section{Part II- buprenorphine definitive study Animals and treatments}

A total of 60 Yorkshire-Landrace $\mathrm{x}$ Duroc male piglets (5-days-old, 1.07 to $3.34 \mathrm{~kg} \mathrm{BW)} \mathrm{from} 10$ different litters were used in this study. Sows and piglets were housed in farrowing pens at the University of Guelph Arkell Swine Research Station.

Within each litter, piglets were randomly assigned to one of the following treatments: $0.04 \mathrm{mg} / \mathrm{kg}$ buprenorphine- castrated, $0.04 \mathrm{mg} / \mathrm{kg}$ buprenorphine- uncastrated, saline (castrated control), or sham (uncastrated control). Buprenorphine (BUP) was administered IM at $0.04 \mathrm{mg} / \mathrm{kg}$ (range: $0.2-0.5 \mathrm{~mL} /$ piglet). Saline was given $\mathrm{IM}$ at $0.2 \mathrm{~mL} /$ piglet. The sham treatment group was handled for approximately $30 \mathrm{~s}$ and did not receive an injection. Treatment groups were identified by a symbol ('V', 'X', circle or diamond) marked on each piglet's forehead and back with a black permanent marker prior to castration. This was to ensure that the individual involved in post-castration observations and behavior scoring was blinded to animal treatment. A number was also marked on the back leg of each piglet for individual identification purposes.

\section{Processing procedure}

Piglets were processed as described for the pilot study. Castrations occurred between 8:00 am and 10:00 am. The sham treatment group were the only non-castrated piglets that underwent a simulated castration. All handling and technical procedures were conducted by female researchers to eliminate the potential confound of 
increased stress and an altered pain response in piglets exposed to male researchers, as reported in mice [53].

\section{Behavior recording and scoring}

Video cameras were placed on tripods outside of the farrowing pens and piglets were video recorded pre-procedure for $1 \mathrm{~h}$. Immediately post-castration, piglets were video recorded continuously for $8 \mathrm{~h}$, and $24 \mathrm{~h}$ post-procedure, piglets were recorded for $1 \mathrm{~h}$ (10 h of video data were collected in total for each pen of pigs). Videos were randomized using a random number generator (random.org) and the behavior of each piglet was scored continuously by one experienced observer for the first 15 mins of every hour of video collected using the Observer XT program (Version 12.0: Noldus Information Technology, Wageningen, The Netherlands) according to a detailed ethogram adapted from Hay et al. [2] (Table 2). The observer was blinded as to time point, litter, and piglet treatment; however, castrated piglets could be clearly distinguished from those that had not been castrated. A total of $9000 \mathrm{~min}$ $(150 \mathrm{~h})$ of behavior recordings were scored and analyzed.

Piglet behaviors were analyzed individually and then grouped into active, inactive and pain categories, to assess the piglet's activity level throughout the observation period and the total amount of pain behaviors displayed [7]. Active behaviors included walking, running, playing, nosing, chewing, and suckling. Inactive behaviors included sleeping and awake inactive. Postures were used for this behavioral analysis; piglets that were standing or sitting were scored as active and lying piglets were scored as inactive. Sitting was scored in the active category because most piglets exhibited this posture when rump scratching or suckling and these were considered active behaviors. Pain behaviors included trembling, stiffness, spasms, tail wagging, and rump scratching [2].
Table 2 Ethogram used to score piglet behavior, grouped into feeding, locomotion, non-specific behaviors, pain-related behaviors, posture, and social cohesion (adapted from [2])

\begin{tabular}{|c|c|}
\hline Behaviors & Description \\
\hline Suckling & $\begin{array}{l}\text { Teat in mouth and } \\
\text { suckling movements }\end{array}$ \\
\hline Nosing udder & $\begin{array}{l}\text { Nose in contact with udder, } \\
\text { up and down head movements }\end{array}$ \\
\hline Playing & $\begin{array}{l}\text { Springing, bouncy } \\
\text { movements with littermates }\end{array}$ \\
\hline Agonistic & Biting or fighting other littermates \\
\hline Walking & Moving forward at a normal pace \\
\hline Running & Trot or gallop \\
\hline Awake inactive & No special activity, but awake \\
\hline Sleeping & Lying down, eyes closed \\
\hline Nosing & Snout in contact with a substrate \\
\hline Chewing & Nibbling at littermates or substrates \\
\hline Trembling & Shivering, as with cold \\
\hline Spasms & $\begin{array}{l}\text { Quick and involuntary contractions } \\
\text { of the muscles }\end{array}$ \\
\hline Scratching & $\begin{array}{l}\text { Rubbing the rump against } \\
\text { the floor, pen walls, or littermates }\end{array}$ \\
\hline Tail wagging & $\begin{array}{l}\text { Tail's movements from side } \\
\text { to side (or up and down) }\end{array}$ \\
\hline Stiffness & Lying with extended and tensed legs \\
\hline Lying & Body weight supported by side or belly \\
\hline Sitting & $\begin{array}{l}\text { Body weight supported by } \\
\text { hindquarters and front legs }\end{array}$ \\
\hline Standing & Body weight supported by four legs \\
\hline Kneeling & $\begin{array}{l}\text { Body weight supported by } \\
\text { front carpal joints and hind legs }\end{array}$ \\
\hline Isolated & $\begin{array}{l}\text { Alone or with one littermate } \\
\text { at most, distance of } 40 \mathrm{~cm} \\
\text { separates the animal(s) from } \\
\text { the closest group of littermates }\end{array}$ \\
\hline Desynchronized & $\begin{array}{l}\text { Activity different from that of } \\
\text { most littermates (at least } 75 \% \text { ) }\end{array}$ \\
\hline
\end{tabular}

Table 3 Total number of piglet faces captured for Piglet Grimace Scale scoring

\begin{tabular}{|c|c|c|c|c|c|}
\hline \multirow{2}{*}{$\begin{array}{l}\text { Time } \\
\text { point } \\
\text { (h) }\end{array}$} & \multicolumn{4}{|l|}{ Treatment } & \multirow[t]{2}{*}{ Total } \\
\hline & $0.04 \mathrm{mg} / \mathrm{kg}$ BUP cast & $0.04 \mathrm{mg} / \mathrm{kg}$ BUP uncast & Saline & Sham & \\
\hline pre & 17 & 14 & 17 & 9 & 57 \\
\hline 0 & 18 & 17 & 15 & 11 & 61 \\
\hline 1 & 12 & 21 & 3 & 10 & 46 \\
\hline 2 & 18 & 19 & 11 & 6 & 54 \\
\hline 3 & 23 & 12 & 7 & 8 & 50 \\
\hline 4 & 12 & 15 & 7 & 5 & 39 \\
\hline 5 & 19 & 19 & 10 & 7 & 55 \\
\hline 6 & 14 & 15 & 10 & 8 & 47 \\
\hline 7 & 12 & 13 & 9 & 2 & 36 \\
\hline 24 & 18 & 21 & 15 & 12 & 66 \\
\hline Total & 163 & 166 & 104 & 78 & 511 \\
\hline
\end{tabular}




\section{The Piglet Grimace Scale}

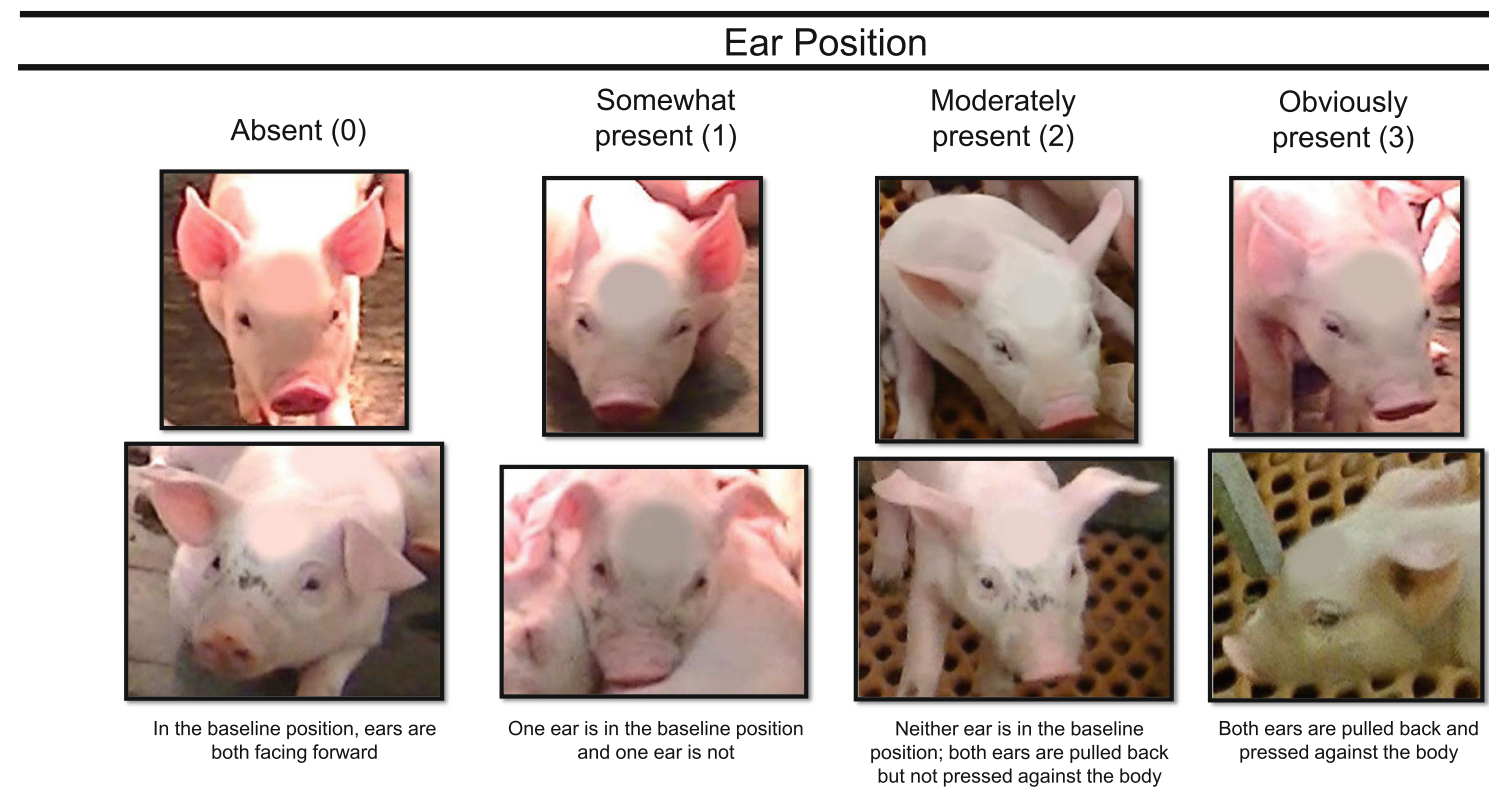

- Determine ear position by looking at the base of the ear (point that connects to the piglet's head)

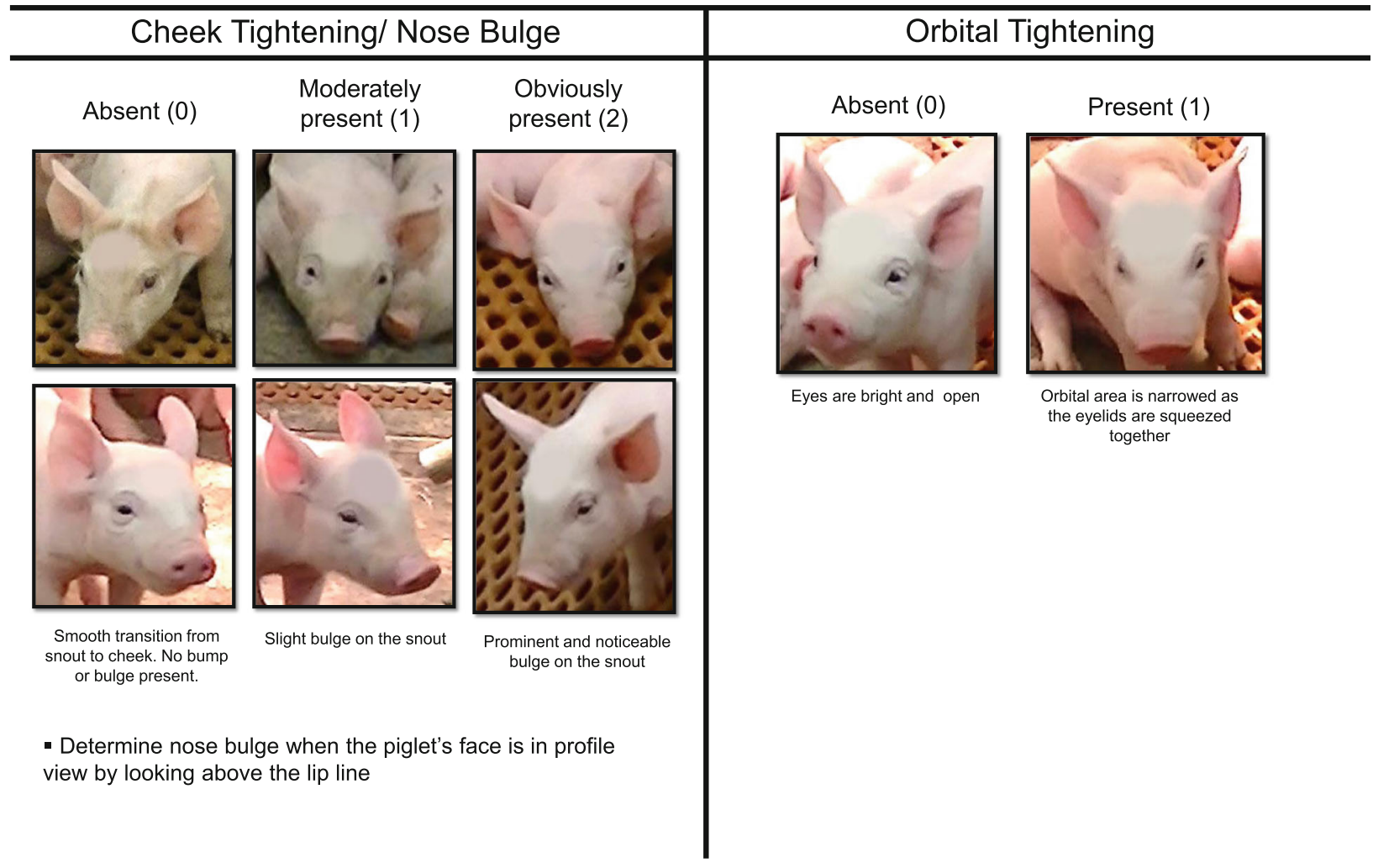

Fig. 8 The Piglet Grimace Scale (PGS) scores ear position, cheek tightening/nose bulge and orbital tightening. The maximum score is 6 


\section{Piglet grimace scale and scoring}

Still images of piglet faces were taken from the first $30 \mathrm{~min}$ of every hour of video data by an individual blinded as to time point and animal treatment using the Everio MediaBrowser 4 program (Pixela Corporation, Osaka, Japan). Whenever a piglet face was in view, the video was paused, and the still image was captured (excluding times when piglets were lying with their head down or sleeping). Taking at least one facial image of each piglet per time point in this study was attempted. A total of 511 images were captured (Table 3). The images were uploaded to Photoshop (Adobe Systems Incorporated, San Jose, CA) prior to scoring to blur the symbol marked on each piglet's forehead. This was to ensure that those scoring the faces were blinded as to treatment. Faces were then randomized into files using a random number generator (random.org).

Four individuals with extensive animal experience were trained to use the Piglet Grimace Scale (Fig. 8) in a 30 min interactive training session prior to scoring study faces. If an image could not be scored reliably, those scoring were instructed to exclude it (3 images were removed in total because of poor image quality). The PGS score for each image was calculated by summing the scores given to each of the facial action units (ear position, cheek tightening/nose bulge and orbital tightening). If more than one image was pulled from the same piglet within one time point, the PGS scores were averaged across images prior to analysis, to prevent issues with pseudo-replication. The final PGS score of each piglet per time point was calculated as a mean of the scores from the four individuals.

\section{Vocalizations}

Vocalizations of each piglet were collected at three points during the study, at initial handling when they were marked with a symbol (marking), when they received their treatment injection (injection) and when they were surgically castrated (incision and castration). A video camera on a tripod was placed as close to the focal piglet's face as possible and recorded each procedure. Vocalizations from the recorded videos were analyzed using Raven Pro 1.5 (Cornell Lab of Ornithology, Ithaca, NY) by two individuals who were blinded as to procedure and piglet treatment. From the spectrograms, maximum frequency $(\mathrm{Hz})$, maximum amplitude $(\mu)$, maximum power $(\mathrm{dB})$ and energy $(\mathrm{dB})$ of each call was determined [43, 54].

\section{Data and statistical analysis}

The total duration of behaviors was converted into a proportion of time that piglets spent demonstrating each behavior prior to analysis to account for periods of time when piglets were out of view and unable to be scored. Normality was evaluated using the univariate procedure in SAS (Statistical Analysis System 9.4, SAS Institute Inc., NC). Data was analyzed with a GLIMMIX procedure with a beta distribution, including time, treatment, litter, and the time $\mathrm{x}$ treatment interaction. Litter was included as a random effect and time was a repeated measure with piglet as the experimental unit. Post hoc tests were conducted on significant factors using the Tukey-Kramer adjustment. Statistical significance was set at $P<0.05$.

The PGS scores were analyzed using a mixed model procedure, including litter, time, treatment, and time $\mathrm{x}$ treatment interaction. Litter was included as a random effect, time was a repeated measure, and piglet was the experimental unit. A post-hoc Tukey's test was conducted for significant outcomes.

Vocalization data was analyzed using a mixed procedure, including litter, treatment, and procedure in the model. Litter was included as a random effect and piglet was the experimental unit. Significant outcomes were further analyzed using a post-hoc Tukey's test. Behavior, PGS and vocalization data were used to assess the effectiveness of buprenorphine treatment in reducing surgical castration pain.

To determine if piglet weight was balanced across treatment groups, post-hoc analysis was performed using a GLM procedure, including litter and treatment in the model.

\section{Abbreviations \\ BUP: Buprenorphine; BW: Body weight; IM: Intramuscular; NSAID: Nonsteroidal anti-inflammatory drug; PGS: Piglet Grimace Scale}

\section{Acknowledgements}

The authors wish to thank Brianne Mercer, Stephanie Cervi, Anna Maystrenko, Tim Thalen, and personnel at the Arkell Swine Research Station for technical assistance.

\section{Funding}

Funding was provided by Ontario Pork (052367), National Pork (052457) and the Ontario Ministry of Agriculture Food and Rural Affairs (27295).

\section{Availability of data and materials}

Most data supporting findings are provided within the text. Individual animal data are available from the corresponding author on request.

\section{Authors' contributions}

AW and PVT conceived of and designed the experiments. AW performed the experiments and analyzed the data. Both authors prepared and edited the final manuscript.

Ethics approval and consent to participate

This study was conducted at Arkell Swine Research Station, an active research facility supported by the University of Guelph and the Ontario Ministry of Agriculture, Food and Rural Affairs (OMAFRA). All animal use and procedures were approved by the University of Guelph Animal Care Committee (Animal Utilization Protocol \#3350). The institution is registered under the Animals for Research Act of Ontario and holds a Good Animal

Practice certificate issued by the Canadian Council on Animal Care.

Consent for publication

Not applicable. 


\section{Competing interests}

The authors declare that they have no competing interests.

\section{Publisher's Note}

Springer Nature remains neutral with regard to jurisdictional claims in published maps and institutional affiliations.

\section{Received: 14 March 2018 Accepted: 9 October 2018}

\section{Published online: 23 October 2018}

\section{References}

1. Sutherland MA. Welfare implications of invasive piglet husbandry procedures, methods of alleviation and alternatives: a review. N Z Vet J. 2015;63:52-7.

2. Hay M, Vulin A, Genin S, Sales P, Prunier A. Assessment of pain induced by castration in piglets: behaviour and physiological responses over the subsequent 5 days. Appl Anim Behav Sci. 2003;82:201-18.

3. Leidig MS, Hertrampf B, Failing K, Schumann A, Reiner G. Pain and discomfort in male piglets during surgical castration with and without local anaesthesia as determined by vocalisation and defense behaviour. Appl Anim Behav Sci. 2009;116:174-8.

4. Kluivers-Poodt M, Houx BB, Robben SRM, Koop G, Lambooij E, Hellebrekers $\sqcup$. Effects of a local anaesthetic and NSAID in castration of piglets, on the acute pain responses, growth and mortality. Animal. 2012;6:1469-75.

5. European Commission. European declaration on alternatives to surgical castration of pigs. 2010. https://ec.europa.eu/food/animals/welfare/practice/ farm/pigs/castration_alternatives_en. Accessed 15 Oct 2017.

6. National Farm Animal Care Council. Code of practice for the care and handling of pigs. 2014. http://www.nfacc.ca/pdfs/codes/pig_code_of_ practice.pdf. Accessed 15 Oct 2017.

7. Viscardi AV, Mercer B, Whatley J, Hoffman H, Turner PV. NSAIDs do not mitigate piglet castration pain based on behavioural and activity monitoring. Proceedings of the $7^{\text {th }}$ International Conference on the Assessment of Animal Welfare at Farm and Group level, Ede, The Netherlands, September 5-8. Wageningen, The Netherlands: De Jong, Koene, Wageningen Academic Publishers; 2017.

8. Papich MG. An update on nonsteroidal anti-inflammatory drugs (NSAIDs) in small animals. Vet Clin Small Anim. 2008;38:1243-61.

9. Chahl LA. Opioids- mechanism of action. Aust Prescr. 1996;19:63-5.

10. Nishimura R, Sakaguchi M, Mochizuki M, Sasaki N, Takahashi H, Tamura H, Takeuchi A. A balanced anesthesia with a combination of xylazine, ketamine and butorphanol and its antagonism by yohimbine in pigs. J Vet Med Sci. 1992;54:615-20.

11. Sakaguchi M, Nishimura R, Sasaki N, Ishiguro T, Tamura H, Takeuchi A. Enhancing effect of butorphanol on medetomidine-induced sedation in pigs. J Vet Med Sci. 1992;54:1183-5.

12. Heinonen ML, Raekallio MR, Oliviero C, Ahokas S, Peltoniemi OAT. Comparison of azaperone-detomidine-butorphanol-ketamine and azaperone-tiletamine-zolazepam for anaesthesia in piglets. Vet Anaesth Analg. 2009:36:151-7.

13. Schöffmann G, Winter P, Palme R, Pollak A, Trittenwein G, Golej J. Haemodynamic changes and stress responses of piglets to surgery during total intravenous anaesthesia with propofol and fentanyl. Lab Anim. 2009; 43:243-8.

14. McGlone JJ, Nicholson RI, Hellman JM, Herzog DN. The development of pain in young pigs associated with castration and attempts to prevent castration-induced behavioral changes. J Anim Sci. 1993;71:1441-6.

15. Hermansen K, Pedersen LE, Olesen HO. The analgesic effect of buprenorphine, etorphine and pethidine in the pig: a randomized double blind cross-over study. Acta pharmacol et toxicol. 1986;59:27-35.

16. Meijer E, van Nes A, Back W, van der Staay FJ. Clinical effects of buprenorphine on open field behaviour and gait symmetry in healthy and lame weaned piglets. Vet J. 2015;206:298-303.

17. Viscardi AV, Hunniford M, Lawlis P, Leach M, Turner PV. Development of a piglet grimace scale to evaluate piglet pain using facial expressions following castration and tail docking: a pilot study. Front Vet Sci. 2017:4:51.

18. Langford DJ, Bailey AL, Chanda ML, Clarke SE, Drummond TE, Echols S, Glick $\mathrm{S}$, Ingrao J, Klassen-Ross T, LaCroix-Fralish ML, Matsumiya L, Sorge RE, Sotocinal SG, Tabaka JM, Wong D, van den Maagdenberg AMJM, Ferrari MD, Craig KD, Mogil JS. Coding of facial expressions of pain in the laboratory mouse. Nat Methods. 2010;7:447-9.
19. Sotocinal SG, Sorge RE, Zaloum A, Tuttle AH, Martin $\amalg$, Wieskopf JS, Mapplebeck JCS, Wei P, Zhan S, Zhang S, McDougall JJ, King OD, Mogil JS. The rat grimace scale: a partially automated method for quantifying pain in the laboratory rat via facial expressions. Mol Pain. 2011;7:55.

20. Keating SCJ, Thomas AA, Flecknell PA, Leach MC. Evaluation of EMLA cream for preventing pain during tattooing of rabbits: changes in physiological, behavioural and facial expression responses. PLoS ONE. 2012. https://doi. org/10.1371/journal.pone.0044437.

21. Costa ED, Minero M, Lebelt D, Stucke D, Canali E, Leach MC. Development of the horse grimace scale (HGS) as a pain assessment tool in horses undergoing routine castration. PLoS One. 2014. https:// doi.org/10.1371/journal.pone.0092281.

22. Guesgen MJ, Beausoleil NJ, Leach M, Minot EO, Stewart M, Stafford KJ. Coding and quantification of a facial expression for pain in lambs. Behav Process. 2016;132:49-56

23. McLennan KM, Rebelo CJB, Corke MJ, Holmes MA, Leach MC, ConstantinoCasas F. Development of a facial expression scale using footrot and mastitis as models of pain in sheep. Appl Anim Behav Sci. 2016;176:19-26.

24. Miller AL, Leach MC. The mouse grimace scale: a clinically useful tool? PLoS One. 2015. https://doi.org/10.1371/journal.pone.0136000.

25. Rollin BE. Annual meeting keynote address: animal agriculture and emerging social ethics for animals. J Anim Sci. 2004;82:955-64.

26. Berger $\mathrm{N}$, Eeg PH. Pain management considerations for laser surgery procedures. In: Veterinary laser surgery: a practical guide. Ames, lowa: Blackwell Publishing; 2006. p. 101-8.

27. Robertson IS, Kent JE, Molony V. Effect of different methods of castration on behavior and plasma cortisol in calves of three ages. Res Vet Sci. 1994;56:8-17.

28. Graf B, Senn M. Behavioural and physiological responses of calves to dehorning by heat cauterization with or without local anaesthesia. Appl Anim Behav Sci. 1999;62:153-71.

29. Rault JL, Lay DC. Nitrous oxide by itself is insufficient to relieve pain due to castration in piglets. J Anim Sci. 2014;89:3318-25.

30. Jongman EC, Borg S, Hemsworth PH. Assessment of pain responses associated with castration of 10-week-old lambs using the Callicrate 'WEE bander' compared with a standard elastrator. Appl Anim Behav Sci. 2016;179:46-52.

31. Di Giminiani P, Edwards SA, Malcolm EM, Leach MC, Herskin MS, Sandercock DA. Characterization of short- and long-term mechanical sensitisation following surgical tail amputation in pigs. Sci Rep. 2017:7:4827.

32. Park SY, van Oord R, van der Staay FJ, Nordquist RE. Social behaviour of pigs: Utrecht University Repository; 2010. https://dspace.library.uu.nl/handle/ 1874/204302.

33. Kumar V, Abbas A, Aster J. Robbins \& Cotran Pathologic Basis of Disease, 9th ed. Amsterdam, NL: Elsevier; 2015.

34. Thiede AJ, Garcia KD, Stolarik DF, Ma J, Jenkins GJ, Nunamaker EA. Pharmacokinetics of sustained-release and transdermal buprenorphine in Göttingen minipigs (Sus scrofa domestica). J Am Assoc Lab Anim Sci. 2014;53:692-9.

35. Canadian Pork Council. Swine Health Ontario. Pain control information for swine. 2016. http://www.swinehealthontario.ca/About-Us/Latest-News-View/ Articleld/2563/Pain-Control-Information-for-Swine. Accessed 25 Jan 2018.

36. Keita A, Pagot E, Prunier A, Guidarini C. Pre-emptive meloxicam for postoperative analgesia in piglets undergoing surgical castration. Vet Anaesth Analg. 2010;37:367-74.

37. O'Connor A, Anthony R, Bergamasco L, Coetzee J, Gould S, Johnson AK, Karriker LA, Marchant-Forde JN, Martineau GS, McKean J, Millman ST, Niekamp S, Pajor EA, Rutherford K, Sprague M, Sutherland M, von Borell E, Dzikamunhenga RS. Pain management in the neonatal piglet during routine management procedures. Part 2: grading the quality of evidence and the strength of recommendations. Anim Health Res Rev. 2014;15:39-62.

38. Leach MC, Klaus K, Miller AL, Scotto di Perrotolo M, Sotocinal SG, Flecknell PA. The assessment of post-vasectomy pain in mice using behaviour and the mouse grimace scale. PLoS One. 2012;7:e35656.

39. Marchant JN, Rudd AR, Mendl MT, Broom DM, Meredity MJ, Corning S, Simmins PH. Timing and causes of piglet mortality in alternative and conventional farrowing systems. Vet Rec. 2000;147:209-14.

40. Herpin P, Damon M, Le Dividich J. Development of thermoregulation and neonatal survival in pigs. Livest Prod Sci. 2002;78:25-45.

41. Pedersen LJ, Berg P, Jørgensen G, Andersen IL. Neonatal piglet traits of importance for survival in crates and indoor pens. J Anim Sci. 2011;89:1207-18 
42. Bovey KE, Widowski TM, Dewey CE, Devillers N, Farmer C, Lessard M, Torrey S. The effect of birth weight and age at tail docking and ear notching on the behavioural and physiological responses of piglets. J Anim Sci. 2014;92:1718-27.

43. Marx G, Horn T, Thielebein J, Knubel B, von Borell E. Analysis of pain-related vocalizations in young pigs. J Sound Vib. 2003;266:687-98.

44. White RG, DeShazer JA, Tressler CJ, Borcher GM, Davey S, Waninge A, Parkhurst AM, Milanuk MJ, Clemens ET. Vocalization and physiological response of pigs during castration with or without a local anesthetic. J Anim Sci. 1995;73:381-6.

45. Axiak SM, Jäggin N, Wenger S, Doherr MG, Schatzmann U. Anaesthesia for castration of piglets: comparison between intranasal and intramuscular application of ketamine, climazolam and azaperone. Schweiz Arch Tierheilkd. 2007;149:395-402.

46. Sutherland MA, Davis BL, Brooks TA, Coetzee JF. The physiological and behavioural response of pigs castrated with and without anesthesia or analgesia. J Anim Sci. 2012;90:2211-21.

47. US Food \& Drug Administration. BupreLab- for the control of post procedural pain in rats. 2014. https:/www.fda.gov/downloads/ AnimalVeterinary/DevelopmentApprovalProcess/MinorUseMinorSpecies/ UCM373292.pdf. Accessed 24 Jan 2018.

48. US Food \& Drug Administration. The index of legally marketed unapproved new animal drugs for minor species. 2017. https://www.fda.gov/ AnimalVeterinary/DevelopmentApprovalProcess/MinorUseMinorSpecies/ ucm125452.htm. Accessed 27 Jul 2018.

49. Centers for Disease Control and Prevention. Opioid overdose: understanding the epidemic. 2017. https://www.cdc.gov/drugoverdose/epidemic/index.html. Accessed 28 Jul 2018.

50. Shadle CC, Meyer JL. Pets, vets, and opioids. 2018. Am Vet. https://www. americanveterinarian.com/journals/amvet/2018/april2018/pets-vets-andopioids? $\mathrm{p}=2$. Accessed $27 \mathrm{Jul} 2018$

51. U.S. Department of agriculture. Opioid misuse in rural America. 2018. https://www.usda.gov/topics/opioids. Accessed 28 Jul 2018.

52. Flecknell P. Analgesia and post-operative care. In: Laboratory animal anaesthesia. 4th ed. Amsterdam, NL: Elsevier; 2015. p. 174.

53. Sorge RE, Martin L, Isbester KA, Sotocinal SG, Rosen S, Tuttle AH, Wieskop JS, Acland EL, Dokova A, Kadoura B, Leger P, Mapplebeck JCS, MCPhail M, Delaney A, Wigerblad G, Schumann AP, Quinn T, Frasnelli J, Svensson Cl, Sternberg WF, Mogil JS. Olfactory exposure to males, including men, causes stress and related analgesia in rodents. Nat Methods. 2014;11:629-32.

54. Taylor AA, Weary DM. Vocal responses of piglets to castration: identifying procedural sources of pain. Appl Anim Behav Sci. 2000;70:17-26.

Ready to submit your research? Choose BMC and benefit from:

- fast, convenient online submission

- thorough peer review by experienced researchers in your field

- rapid publication on acceptance

- support for research data, including large and complex data types

- gold Open Access which fosters wider collaboration and increased citations

- maximum visibility for your research: over $100 \mathrm{M}$ website views per year

At $\mathrm{BMC}$, research is always in progress.

Learn more biomedcentral.com/submissions 